\title{
Effects of enhanced recovery after surgery practices on postoperative recovery and length of stay after unilateral primary total hip or knee arthroplasty in a private hospital
}

\author{
Marvin MT Chung *, Jacobus KF Ng, FY Ng, PK Chan, KY Chiu
}

\section{A B S T R A C T}

Introduction: Enhanced recovery after surgery (ERAS) practices improve postoperative recovery and reduce postoperative length of stay (LOS) in patients undergoing primary total hip arthroplasty (THA) or total knee arthroplasty (TKA). Our study investigated whether these promising results could be reproduced in a private hospital setting.

Methods: In total, 228 patients were included in the study cohort: the conventional group comprised 117 patients from 2012 to 2014, while the ERAS group comprised 111 patients from 2017 to 2018. All patients had undergone unilateral primary THA or TKA at a private hospital in Hong Kong. The outcome was postoperative LOS; factors affecting LOS were also investigated.

Results: No significant differences were found in any baseline parameters between the two groups of patients. The mean LOS was significantly shorter in the ERAS group than in the conventional group $(3.28 \pm 1.04$ vs $5.16 \pm 2.06$ days, $\mathrm{P}<0.001)$. Moreover, a significantly greater proportion of patients could be discharged on or before postoperative day 3 in the
This article was published on 3 Dec 2021 at www.hkmj.org. in LOS was observed between general ward and private ward patients $(3.06 \pm 0.59$ vs $3.66 \pm 1.46$ days, $\mathrm{P}=0.003$ ). Sex, age, and nature of surgery (TKA vs THA) did not have significant effects on LOS.

Conclusions: The ERAS practices yielded a significant improvement in postoperative LOS, compared to conventional practices, among patients who underwent unilateral primary THA or TKA in a private hospital.

\section{Hong Kong Med J 2021;27:437-43 \\ https://doi.org/10.12809/hkmj208587}

${ }^{1}$ MMT Chung *, MB, BS, MRCSEd

2,3 JKF Ng, FHKAM (Anaesthesiology)

${ }^{2}$ FY Ng, FHKCOS, FHKAM (Orthopaedic Surgery)

${ }^{1}$ PK Chan, FHKCOS, FHKAM (Orthopaedic Surgery)

${ }^{3,4}$ KY Chiu, FHKCOS, FHKAM (Orthopaedic Surgery)

${ }^{1}$ Department of Orthopaedics and Traumatology, Queen Mary Hospital, Hong Kong

2 Private practice, Hong Kong

${ }^{3}$ Hong Kong Sanatorium \& Hospital, Hong Kong

${ }^{4}$ Department of Orthopaedics and Traumatology, The University of Hong Kong, Hong Kong

* Corresponding author: marvinchung@ortho.hku.hk

New knowledge added by this study

- Enhanced recovery after surgery (ERAS) practices in total joint arthroplasty improve postoperative length of stay in the private hospital setting, similar to previous findings in public joint replacement centres.

- Among patients who underwent unilateral primary total hip or knee arthroplasty in a private hospital, postoperative length of stay was lower for patients in general wards than for patients in private wards.

Implications for clinical practice or policy

Standardised ERAS practices could be implemented as a protocol by private hospitals in Hong Kong.

- Although full ERAS implementation may be difficult to achieve in a short period of time, gradual addition of ERAS components could improve patient outcomes in private hospitals.

\section{Introduction}

Enhanced recovery after surgery (ERAS) practices were developed in the 1990s whereby multiple modalities of intervention ${ }^{1}$ were introduced perioperatively to improve postoperative recovery, ${ }^{2}$ reduce length of stay (LOS), ${ }^{3}$ and lower the incidence of perioperative morbidity. ${ }^{4}$ These practices have been widely adopted in many surgical fields, ${ }^{5-7}$ including orthopaedics. ${ }^{8}$ Further enhancements of postoperative pain management, venous thromboembolism prophylaxis, and early mobilisation have led to encouraging results in primary total hip arthroplasty (THA) and total knee arthroplasty (TKA); such results have included earlier recovery, ${ }^{9} \mathrm{LOS}$ reduction, ${ }^{10}$ improved function, ${ }^{11}$ and lower venous thromboembolism incidence ${ }^{12}$ without declines in patient satisfaction, postoperative complication rate, ${ }^{13}$ or cost. ${ }^{14}$ The development of 


\section{術後加速康復療程對私家醫院全顝及全膝關節 置換手術後復元及住院時間之影響 \\ 鍾汶庭、吳國夫、吳富源、陳秉強、曲廣運}

引言：術後加速康復療程（ERAS）能促進全顝及全膝關節置換手術 後復元及減少住院時間。本研究旨在評估ERAS能否在私家醫院達到 相同效果。

方法：共有228名患者被納入研究, 其中117名患者於2012-2014年間 接受常規手術, 111名患者於2017-2018年間接受ERAS療程。全部患 者均在同一間香港私家醫院接受單邊全髖或全膝關節置換手術。常規 手術及ERAS療程患者之住院時間將進行比較。

結果：兩組患者的基本因素沒有顯著分別。ERAS顯著縮短住院時間

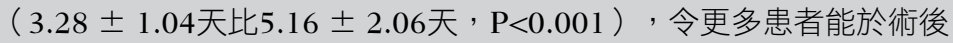
3 天內出院 $(77.5 \%$ 比 $13.7 \%, \mathrm{P}<0.001)$ 。普通病房患者比私家病房 患者的住院時間略低（3.06 \pm 0.59 天比 $3.66 \pm 1.46$ 天, $\mathrm{P}=0.003)$; 而性別、年齡和關節種類則沒有顯著分別。

結論：ERAS能於私家醫院促進全髋及全膝關節置換手術後復元及減 少住院時間。
THA or TKA by the senior author (KYC) at Hong Kong Sanatorium \& Hospital, Hong Kong, were included in the study cohort. Patients with revision arthroplasty, one-stage bilateral arthroplasty, and unicompartmental knee arthroplasty were excluded. Because ERAS practices were progressively implemented from 2015 to 2016, we allocated patients who were treated from 2012 to 2014 into the conventional group and patients who were treated from 2017 to 2018 into the ERAS group.

\section{Similarities between enhanced recovery after surgery and conventional practices}

Our ERAS practices were generally similar to conventional practices. Most patients underwent surgery on the morning after an evening admission. Most patients received spinal anaesthesia unless contra-indicated (eg, ankylosing spondylitis, severe spinal deformity, coagulopathy, or fixed cardiac output state); routine sedation (using intravenous midazolam and propofol) was also conducted to improve patient comfort. Cementless THA systems, either a Pinnacle acetabular cup with a Summit femoral stem (DePuy, Warsaw [IN], US) or an R3 acetabular cup with a Synergy femoral stem (Smith \& Nephew, Auckland, New Zealand), were implemented by means of a posterolateral approach. Total knee arthroplasty was performed using a medial parapatellar approach with thigh tourniquet and conventional instruments. Cemented rotating platform TKA systems were used: either a Legacy Posterior Stabilised Flex Mobile prosthesis (Zimmer, Warsaw [IN], US) or an Attune prosthesis (DePuy). A Foley urinary catheter was inserted only on urinary retention with bladder volume of $>800 \mathrm{~mL} .^{21}$ Prophylactic antibiotics were administered on the induction of anaesthesia, then continued for 2 days after surgery. Prophylaxis against venous thromboembolism, both pharmacological (with subcutaneous enoxaparin) and mechanical (with a sequential compression device), was routinely implemented. Patients were discharged home when they could safely exit their beds without assistance and stably walk using an assistive device without any sign of complications.

\section{Differences between enhanced recovery after surgery and conventional practices}

\section{Steroid administration}

When using ERAS practices, a higher dose of intravenous steroid is administered on the induction of anaesthesia for both THA and TKA. In the conventional group, 4 to $8 \mathrm{mg}$ of dexamethasone was administered; in the ERAS group, $125 \mathrm{mg}$ of methylprednisolone (equivalent to $25 \mathrm{mg}$ of dexamethasone) was administered instead..$^{22}$ Notably, high-dose glucocorticoids before arthroplasty are 
reportedly safe and recommended for routine use. $^{23}$

\section{Management of pain, nausea, and vomiting}

In the conventional group, no standard pain control regimen was established. Pain medications were prescribed at the discretion of anaesthetists or surgeons, including the use of femoral nerve block and postoperative patient-controlled analgesia pump. Pain management was standardised and optimised in the ERAS group, particularly for patients undergoing TKA. Pre-emptive analgesia was implemented, such that patients routinely began oral pregabalin and transdermal buprenorphine patch treatments before surgery. Preventive analgesia was also employed both intra- and post-operatively. A periarticular "cocktail" injection of local infiltrative analgesia ${ }^{24}$ consisting of ropivacaine, ketorolac, and 1:1000 adrenaline-was injected into the posterior joint capsule before implantation of the prosthesis; it was also injected into the subcutaneous layer anteriorly and intra-articularly during wound closure. After surgery, patients received multimodal oral analgesia including regular cyclooxygenase- 2 inhibitors or non-steroidal anti-inflammatory drugs, pregabalin, and paracetamol. Buprenorphine patch treatment was maintained for 5 to 7 days. Patient-controlled analgesia was omitted when using ERAS practices. In contrast, the pain control requirement was lower for patients undergoing THA. In both conventional and ERAS groups, local anaesthetic (bupivacaine) was injected into the subcutaneous plane before skin closure, while oral paracetamol was prescribed after surgery. After discharge from the hospital, patients who underwent TKA were administered non-steroidal anti-inflammatory drugs, pregabalin, and paracetamol for up to 5 weeks after surgery; most patients undergoing THA were prescribed paracetamol alone.

Prophylactic intravenous palonosetron was routinely administered to prevent postoperative nausea and vomiting; intravenous metoclopramide was used to manage breakthrough symptoms.

\section{Blood management}

Tranexamic acid was routinely used in the ERAS group to minimise bleeding and the need for transfusion. For patients undergoing TKA, $1 \mathrm{~g}$ of tranexamic acid was injected intra-articularly after deep layer closure. No routine use of tranexamic acid was adopted in conventional practices. A deep drain was used when adhering to conventional practices but not when adhering to ERAS practices. For patients undergoing THA, intravenous tranexamic acid was administered at the same time as induction of anaesthesia; a deep drain was also used and removed the next morning.

\section{Sleep management}

While hypnotics were only administered on request when in the conventional group, patients in the ERAS group were routinely prescribed hypnotics the night before surgery and the first 2 to 3 days after surgery. This helped patients in the ERAS group to comply with the rehabilitation programme after surgery.

\section{Same-day rehabilitation}

Same-day or day-zero rehabilitation was implemented in the ERAS group. Patients in the conventional group had bed rest on the day of surgery, then began mobilisation on postoperative day 1. Conversely, patients in the ERAS group who underwent morning surgery were encouraged to mobilise in the afternoon or evening on the same day, under physiotherapist supervision.

\section{Outcomes}

The outcome was postoperative LOS, which was denoted by the number of days after surgery when the patient was discharged from the hospital. The day of surgery was regarded as postoperative day 0 . Discharge criteria remained consistent throughout the study period (ie, safe exit from bed without assistance and stable walking using an assistive device), as described above. The proportion of patients discharged on or before postoperative day 3 in each group was compared. We also investigated the effects of age, sex, nature of surgery (THA versus TKA), and class of hospital bed (general versus private ward) on LOS.

\section{Statistical analysis}

Patient data were anonymously entered into an encrypted file to ensure privacy. Data analysis was performed using SPSS (Window version 26.0; IBM Corp, Armonk [NY], US). The Chi squared test, independent samples $t$ test with two-tailed significance, and one-way analysis of variance were used for comparisons. A P value of $<0.05$ was considered statistically significant.

\section{Results}

\section{Baseline parameters}

In total, 228 patients were included: 117 in the conventional group and 111 in the ERAS group. The mean and median ages did not significantly differ between the conventional and ERAS groups (Table 1). Most patients were aged between 50 and 89 years $(89.7 \%$ in the conventional group and $97.2 \%$ in the ERAS group); however, the distribution of ages did not significantly differ between groups. The distributions of sex, nature of surgery, and class of hospital bed also did not significantly differ between the conventional and ERAS groups (Table 1). 
TABLE I. Baseline parameters

\begin{tabular}{|c|c|c|c|}
\hline & $\begin{array}{c}\text { Conventional } \\
(n=117)\end{array}$ & ERAS $(n=111)$ & $P$ value \\
\hline \multicolumn{4}{|l|}{ Age, y } \\
\hline Mean $( \pm$ SD) & $67.9 \pm 12.4$ & $69.6 \pm 9.2$ & $0.253^{*}$ \\
\hline Median (range) & $68(26-100)$ & $69(46-92)$ & - \\
\hline \multicolumn{4}{|l|}{$\operatorname{Sex}(\%)$} \\
\hline Female & 66.7 & 60.4 & $0.323^{\dagger}$ \\
\hline Male & 33.3 & 39.6 & \\
\hline \multicolumn{4}{|c|}{ Nature of surgery (\%) } \\
\hline TKA & 57.3 & 53.2 & $0.533^{\dagger}$ \\
\hline THA & 42.7 & 46.8 & \\
\hline \multicolumn{4}{|c|}{ Class of hospital bed (\%) } \\
\hline General & 62.4 & 63.1 & $0.917^{\dagger}$ \\
\hline Private & 37.6 & 36.9 & \\
\hline \multicolumn{4}{|l|}{ Age-group (\%) } \\
\hline $20-29$ & 1.7 & 0 & $0.366^{\dagger}$ \\
\hline $30-39$ & 0.9 & 0 & \\
\hline $40-49$ & 6.8 & 1.8 & \\
\hline $50-59$ & 9.4 & 11.7 & \\
\hline $60-69$ & 34.2 & 37.8 & \\
\hline $70-79$ & 29.9 & 35.1 & \\
\hline $80-89$ & 16.2 & 12.6 & \\
\hline $90+$ & 0.9 & 0.9 & \\
\hline
\end{tabular}

Abbreviations: ERAS = enhanced recovery after surgery; SD = standard deviation;

THA = total hip arthroplasty; TKA = total knee arthroplasty

* Independent-samples $t$ test

+ Pearson Chi squared test

TABLE 2. Comparison of postoperative length of stay

\begin{tabular}{lccc}
\hline & $\begin{array}{c}\text { Conventional } \\
(\mathbf{n}=\mathbf{1 1 7})\end{array}$ & ERAS $(\mathbf{n = 1 1 1 )}$ & P value \\
\hline Length of stay, d & & & \\
Mean ( \pm SD) & $5.16 \pm 2.06$ & $3.28 \pm 1.04$ & $<0.001^{\star}$ \\
Median (range) & $5(3-16)$ & $3(2-10)$ & - \\
$\begin{array}{l}\text { Discharged on or before } \\
\text { postoperative day 3 (\%) }\end{array}$ & 13.7 & 77.5 & $<0.001^{\star}$ \\
\hline
\end{tabular}

Abbreviations: ERAS = Enhanced recovery after surgery; SD = standard deviation

* Independent-samples $t$ test
TABLE 3. Factors affecting length of hospital stay after THA or TKA

\begin{tabular}{lcc}
\hline & \multicolumn{2}{c}{ Length of stay (days) } \\
\cline { 2 - 3 } & $\begin{array}{c}\text { Conventional } \\
(\mathbf{n}=\mathbf{1 1 7})\end{array}$ & ERAS $(\mathbf{n}=\mathbf{1 1 1})$ \\
\hline Sex & $5.35 \pm 2.25$ & $3.27 \pm 1.23$ \\
\hline Female & $4.79 \pm 1.59$ & $3.30 \pm 0.67$ \\
\hline Male & $0.174^{\star}$ & $0.895^{\star}$ \\
\hline P value & & \\
\hline Nature of surgery & $5.40 \pm 2.18$ & $3.27 \pm 0.76$ \\
\hline TKA & $4.84 \pm 1.87$ & $3.29 \pm 1.29$ \\
\hline THA & $0.145^{\star}$ & $0.931^{\star}$ \\
\hline P value & & \\
\hline Class of hospital bed & $5.03 \pm 1.89$ & $3.06 \pm 0.59$ \\
\hline General & $5.39 \pm 2.34$ & $3.66 \pm 1.46$ \\
\hline Private & $0.364^{*}$ & $0.003^{*}$ \\
\hline P value & & \\
\hline
\end{tabular}

Abbreviations: ERAS = enhanced recovery after surgery; THA = total hip arthroplasty; TKA = total knee arthroplasty

* Independent-samples $t$ test

\section{Factors affecting postoperative length of stay}

Subgroup analysis was performed to examine the effects of sex, nature of surgery, class of hospital bed (Table 3), and age-group (Fig) on LOS.

In the conventional group, there were no significant differences in mean LOS between female and male patients, patients receiving TKA and patients receiving THA, or general ward and private ward patients (Table 3). One-way analysis of variance showed a significant difference in mean LOS among age-groups ( $\mathrm{F}[7,109]=2.58, \mathrm{P}=0.017)$ [Fig]. The mean LOS generally increased as age increased from the third decade ( 3 days) to the ninth decade (7 days); however, two patients in the 20-29 agegroup had exceptionally long hospital stays.

In the ERAS group, there were no significant differences in mean LOS between female and male patients or between patients receiving TKA and patients receiving THA (Table 3). One-way analysis of variance showed that age did not have a significant effect on the mean $\operatorname{LOS}(\mathrm{F}[5,105]=1.13, \mathrm{P}=0.348)$ [Fig]. However, the mean LOS significantly differed between general ward and private ward patients (3.06 \pm 0.59 vs $3.66 \pm 1.46$ days, $\mathrm{P}=0.003)$ [Table 3].

\section{Complication and re-admission}

No postoperative complications or instances of 30-day re-admission were observed among patients who underwent TKA. Among patients who underwent THA, three (two from the conventional group, one from the ERAS group) had complications. In the conventional group, 
one patient with spondyloepiphyseal dysplasia experienced dislocation during in-patient stay, which required closed reduction; one patient experienced dislocation during postoperative week 3 , which required re-admission and revision to offset the liner and a longer neck hip ball to improve soft tissue tension. In the ERAS group, one patient had periprosthetic femoral fracture after an accidental fall on postoperative day 13 , which required readmission with revision to the long cementless stem, as well as cable fixation. No patients in either group experienced postoperative wounds or periprosthetic infections.

\section{Discussion}

Despite more efficient service provision, postoperative LOS in private hospitals might be limited by confounders that surgeons cannot control (eg, patient preference and financial factors). ${ }^{25}$ Nevertheless, it was unsurprising that our results were consistent with previous literature: ERAS practices are effective for reducing the LOS after unilateral primary arthroplasty.

Regarding factors that affect postoperative LOS, a significant difference in the mean LOS was observed between general ward and private ward patients in the ERAS group. In public hospitals, the LOS among patients with worse socio-economic backgrounds is often limited by inadequate social support from family after discharge ${ }^{26}$ or a suboptimal home environment (eg, non-lift landing flats in older urban buildings). ${ }^{27}$ While placement issues are rarely problematic for patients in private hospitals, ${ }^{28}$ a possible explanation for the difference in LOS between general ward and private ward patients, where the cost difference is on average 5 times higher, is that patients with better socio-economic backgrounds may have higher expectations for surgical outcomes ${ }^{29}$; thus, they may tolerate longer hospital stays for rehabilitation, despite the higher costs of such stays. Private insurance is also reportedly an independent predictor of discharge delay despite objective readiness for discharge $\mathrm{e}^{30}$; however, we presumed that the effect of insurance was not applicable in the present study because fewer than $10 \%$ of patients in our cohort had no insurance coverage. Furthermore, no significant differences in the mean LOS were noted with regard to the nature of surgery, sex, or age in the ERAS group. These findings may be related to the use of standardised ERAS practices and perioperative protocols, which have minimised variation in patient management. ${ }^{31}$

The implementation of ERAS practices in private hospitals is potentially beneficial to all stakeholders (including hospital administrators) because it facilitates hospital bed availability, while reducing costs via shorter convalescence duration and reduced morbidity. ${ }^{32}$ However, there are some

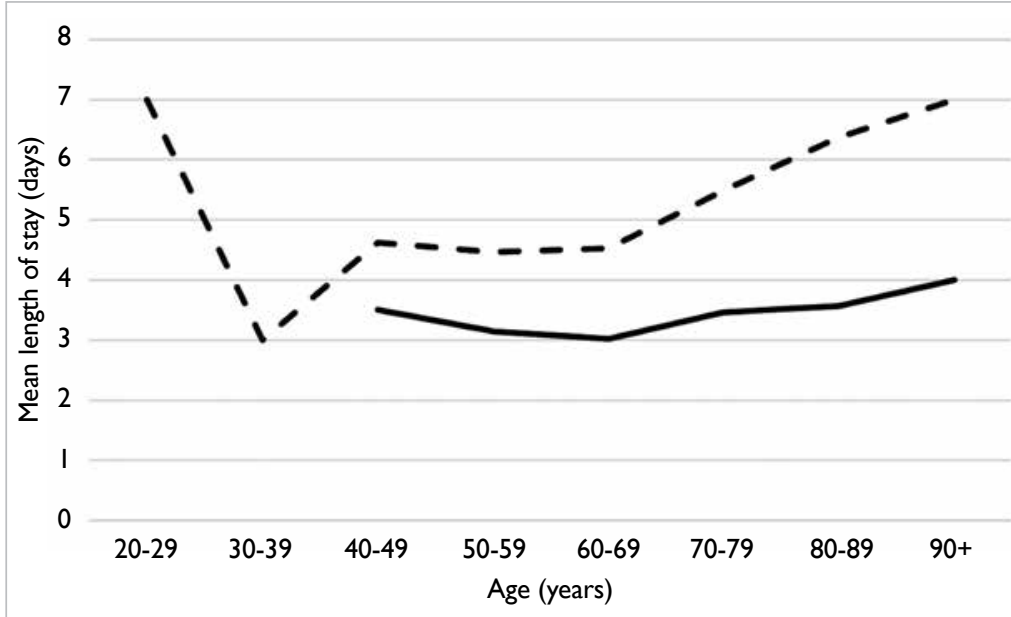

FIG. Postoperative length of hospital stay according to age-group for conventional recovery (dashed line) and enhanced recovery after surgery (solid line)

important challenges for surgeons who wish to initiate ERAS practices in private centres. These challenges include occasional requirements for minor alterations in ward environments, changes in anaesthesia technique, rapid turnover of inhouse surgical staff, and noncompliance with ERAS practices. ${ }^{33}$ Furthermore, a large caseload might be necessary to attract a dedicated multidisciplinary team for the sustainable development of ERAS practices in private centres. While it may be challenging to achieve full ERAS implementation in a short period of time, the stepwise addition of ERAS components might improve patient outcomes in private hospitals. ${ }^{34}$

There were some limitations in this study. First, this study used a retrospective design without randomisation, which may have led to imbalance and bias in the results. Second, this study only involved patients from a single surgeon; thus, the sample size was small. Third, differences in functional status and co-morbidities were not considered in the analysis, as the electronic health record sharing system between public and private hospitals was only established in 2016 so complete acquisition of patient's parameters was not possible. Finally, other clinical outcome parameters and patient satisfaction were not investigated; these will be examined in a future study, where a thorough documentation in patient reported outcome measure and clinicianbased outcome measure will improve the validity of results.

In conclusion, ERAS practices produced significant improvement in mean postoperative LOS, compared to conventional practices, for patients who underwent unilateral primary THA or TKA in a private hospital. Specifically, a significantly greater proportion of patients in the ERAS group were able 
to return home on or before postoperative day 3 . The findings indicate that the good outcomes of ERAS practices in public joint replacement centres can be reproduced in private hospitals with sufficient caseloads and consistent implementation of ERAS practices.

\section{Author contributions}

Concept or design: KY Chiu.

Acquisition of data: MMT Chung.

Analysis or interpretation of data: MMT Chung.

Drafting of the manuscript: MMT Chung, JKF Ng, FY Ng, PK Chan.

Critical revision of the manuscript for important intellectual content: KY Chiu.

All authors had full access to the data, contributed to the study, approved the final version for publication, and take responsibility for its accuracy and integrity.

\section{Conflicts of interest}

All authors have disclosed no conflicts of interest.

\section{Declaration}

The results of this study were presented in the Hong Kong Orthopaedic Association 40th Annual Congress in Hong Kong (31 October to 1 November 2020).

\section{Funding/support}

This research received no specific grant from any funding agency in the public, commercial, or not-for-profit sectors.

\section{Ethics approval}

This study was approved by the Hong Kong Sanatorium \& Hospital Medical Group Research Committee (Ref RC-201925). The requirement for patient consent was waived for this retrospective study.

\section{References}

1. Kehlet H. Multimodal approach to postoperative recovery. Curr Opin Crit Care 2009;15:355-8.

2. Kehlet H, Dahl JB. Anaesthesia, surgery, and challenges in postoperative recovery. Lancet 2003;362:1921-8.

3. Kehlet H. Fast-track hip and knee arthroplasty. Lancet 2013;381:1600-2.

4. Rogers LJ, Bleetman D, Messenger DE, et al. The impact of enhanced recovery after surgery (ERAS) protocol compliance on morbidity from resection for primary lung cancer. J Thoracic Cardiovasc Surg 2018;155:1843-52.

5. Geltzeiler CB, Rotramel A, Wilson C, Deng L, Whiteford MH, Frankhouse J. Prospective study of colorectal enhanced recovery after surgery in a community hospital. JAMA Surg 2014;149:955-61.

6. Melnyk M, Casey RG, Black P, Koupparis AJ. Enhanced recovery after surgery (ERAS) protocols: time to change practice? Can Urol Assoc J 2011;5:342-8.

7. Scheib SA, Thomassee M, Kenner JL. Enhanced recovery after surgery in gynecology: a review of the literature. Minim Invasive Gynecol 2019;26:327-43.

8. Andersen LØ, Gaarn-Larsen L, Kristensen BB, Husted H,
Otte KS, Kehlet H. Subacute pain and function after fasttrack hip and knee arthroplasty. Anaesthesia 2009;64:50813.

9. Wu CL, Raja SN. Treatment of acute postoperative pain. Lancet 2011;377:2215-25.

10. Auyong DB, Allen CJ, Pahang JA, Clabeaux JJ, MacDonald KM, Hanson NA. Reduced length of hospitalization in primary total knee arthroplasty patients using an updated enhanced recovery after surgery (ERAS) pathway. J Arthroplasty 2015;30:1705-9.

11. Pua YH, Ong PH. Association of early ambulation with length of stay and costs in total knee arthroplasty: retrospective cohort study. Am J Phys Med Rehabil 2014;93:962-70.

12. Pearse EO, Caldwell BF, Lockwood RJ, Hollard J. Early mobilisation after conventional knee replacement may reduce the risk of postoperative venous thromboembolism. J Bone Joint Surg Br 2007;89:316-22.

13. Zhu S, Qian W, Jiang C, Ye C, Chen X. Enhanced recovery after surgery for hip mand knee arthroplasty: a systematic review and meta-analysis. Postgrad Med J 2017;93:73642.

14. Duncan CM, Hall Long K, Warner DO, Hebl JR. The economic implications of a multimodal analgesic regimen for patients undergoing major orthopaedic surgery: a comparative study of direct costs. Reg Anesth Pain Med 2009;34:301-7.

15. Duggal S, Flics S, Cornell CN. Introduction of clinical pathways in orthopedic surgical care: the experience of the hospital for special surgery. In: Ronald MacKenzie C, Cornell CN, Memtsoudis SG, editors. Perioperative Care of the Orthopedic Patient. New York: Springer; 2014: 365-71.

16. Husted H. Fast-track hip and knee arthroplasty: clinical and organizational aspects. Acta Orthop Suppl 2012;83:139.

17. Christelis N, Wallace S, Sage CE, et al. An enhanced recovery after surgery program for hip and knee arthroplasty. Med J Aust 2015;202:363-8.

18. Soffin EM, YaDeau JT. Enhanced recovery after surgery for primary hip and knee arthroplasty: a review of the evidence. Br J Anaesth 2016;117(Suppl 3):iii62-72.

19. Yan CH, Chiu KY, Ng FY. Total knee arthroplasty for primary knee osteoarthritis: changing pattern over the past 10 years. Hong Kong Med J 2011;17:20-5.

20. Hospital Authority, Hong Kong SAR Government. Elective total joint replacement surgery. 2019. Available from: https://www.ha.org.hk/visitor/ha visitor_index.asp?Content_ID $=221223 \&$ Lang $=E N \% 20$ G\&Dimension=100\&Parent_ID $=214172 \& V e r=$ HTML . Accessed 25 Feb 2020.

21. Bjerregaard LS, Hornum U, Troldborg C, Bogoe S, Bagi P, Kehlet $\mathrm{H}$. Postoperative urinary catheterization thresholds of 500 versus $800 \mathrm{ml}$ after fast-track total hip and knee arthroplasty: a randomized, open-label, controlled trial. Anesthesiology 2016;124:1256-64.

22. Lunn TH, Kristensen BB, Andersen LØ, et al. Effect of high-dose preoperative methylprednisolone on pain and recovery after total knee arthroplasty: a randomized, placebo-controlled trial. Br J Anaesth 2011;106:230-8.

23. Kehlet H, Lindberg-Larsen V. High-dose glucocorticoid before hip and knee arthroplasty: to use or not to use-that's the question. Acta Orthop 2018;89:477-9. 
24. Ng FY, Ng JK, Chiu KY, Yan CH, Chan CW. Multimodal periarticular injection vs continuous femoral nerve block after total knee arthroplasty: a prospective, crossover, randomized clinical trial. J Arthroplasty 2012;27:1234-8.

25. Badham J, Brandrup J. Length of stay comparisons for private and public hospitals. Aust Health Rev 2000;23:16270 .

26. Freitas A, Silva-Costa T, Lopes F, et al. Factors influencing hospital high length of stay outliers. BMC Health Serv Res 2012;12:265.

27. Waring J, Marshall F, Bishop S, et al. An ethnographic study of knowledge sharing across the boundaries between care processes, services and organisations: the contributions to 'safe' hospital discharge. Southampton (UK): NIHR Journals Library; Sep 2014.

28. Perelman J, Closon MC. Impact of socioeconomic factors on in-patient length of stay and their consequences in per case hospital payment systems. J Health Serv Res Policy 2011;16:197-202.

29. Li X, Galvin JW, Li C, Agrawal R, Curry EJ. The impact of socioeconomic status on outcomes in orthopaedic surgery. J Bone Joint Surg Am 2020;102:428-44.

30. Celio DA, Poggi R, Schmalzbauer M, Rosso R, Majno P, Christoforidis D. ERAS, length of stay and private insurance: a retrospective study. Int J Colorectal Dis 2019;34:1865-70

31. Barbieri A, Vanhaecht K, Van Herck P, et al. Effects of clinical pathways in the joint replacement: a meta-analysis. BMC Med 2009;7:32.

32. Stowers MD, Lemanu DP, Hill AG. Health economics in enhanced recovery after surgery programs. Can J Anaesth 2015;62:219-30.

33. Kahokehr A, Sammour T, Zargar-Shoshtari K, Thompson L, Hill AG. Implementation of ERAS and how to overcome the barriers. Int J Surg 2009;7:16-9.

34. Tan NL, Hunt JL, Gwini SM. Does implementation of an enhanced recovery after surgery program for hip replacement improve quality of recovery in an Australian private hospital: a quality improvement study. BMC Anesthesiol 2018;18:64. 